\title{
FITOTECNIA
}

\section{PRODUTIVIDADE DE RÚCULA E TOMATE EM FUNÇÃO DA ADUBAÇÃO N E P ORGÂNICA E MINERAL $\left(^{\mathbf{1}}\right)$}

\author{
MARIO LUIZ CAVALLARO JÚNIOR $\left({ }^{2}\right)$; PAULO ESPÍNDOLA TRANI $\left(3^{*}\right)$; \\ FRANCISCO ANTÔNIO PASSOS $\left(\left(^{*}\right)\right.$; JORGE KUHN NETO $\left({ }^{4}\right)$; SEBASTIÃO WILSON TIVELLI $\left({ }^{5}\right)$
}

\begin{abstract}
RESUMO
Visando comparar a eficácia de diferentes fertilizantes minerais e orgânicos, fontes de $\mathrm{N}$ e $\mathrm{P}$, foram instalados experimentos com rúcula, sob cultivo protegido, no Instituto Agronômico, Campinas (SP), de outubro a novembro de 2004, e com tomate, no Sítio São João, Elias Fausto (SP), de setembro de 2004 a fevereiro de 2005. Para rúcula estudaram-se quatro doses de N $\left(0 ; 50 ; 100 ; 150 \mathrm{~kg} \mathrm{ha}^{-1}\right.$ de N) e quatro doses de P $(0 ; 100 ; 200$; $300 \mathrm{~kg} \mathrm{ha}^{-1}$ de $\mathrm{P}_{2} \mathrm{O}_{5}$ ) em pré-semeadura e em cobertura, utilizando-se os fertilizantes MAP; DAP; farinha de casco e chifres (FCC) e farinha de ossos (FO). Para tomate, foram estabelecidos dois experimentos: no primeiro, estudaram-se quatro doses de $\mathrm{N}$ em cobertura $\left(0 ; 133 ; 266\right.$ e $\left.399 \mathrm{~kg} \mathrm{ha}^{-1} \mathrm{de} \mathrm{N}\right)$, utilizando-se nitrato de amônio (NA) e FCC, com dose fixa de P no pré-transplante, com o superfosfato triplo (ST). No segundo estudaram-se quatro doses de $\mathrm{P}$ no pré-transplante $\left(0 ; 250 ; 500 ; 750 \mathrm{~kg} \mathrm{ha}^{-1}\right.$ de $\left.\mathrm{P}_{2} \mathrm{O}_{5}\right)$, utilizando-se ST e FO, com dose fixa de $\mathrm{N}$ em cobertura, como NA. Com a adubação com $75 \mathrm{~kg} \mathrm{ha}^{-1}$ de $\mathrm{N}$ e $300 \mathrm{~kg}^{-1}$ ha $\mathrm{P}_{2} \mathrm{O}_{5}$ do MAP + DAP na présemeadura e com $75 \mathrm{~kg} \mathrm{ha}^{-1}$ de $\mathrm{N}$ da FCC em cobertura foram proporcionadas produções maiores de rúcula. A adubação orgânica com FCC foi mais eficaz quando aplicada por ocasião da pré-semeadura. Concluiu-se que FCC foi a fonte mais eficaz de N em relação ao NA para produção e massa média dos frutos de tomate e ST, como fonte de $\mathrm{P}$ em relação à $\mathrm{FO}$, para produção de tomate.
\end{abstract}

Palavras-chave: Eruca sativa, Lycopersicum esculentum, farinha de casco e chifres, farinha de ossos, adubação nitrogenada, adubação fosfatada.

\section{ABSTRACT \\ ROCKET SALAD AND TOMATO YIELD CORRELATED TO ORGANIC AND MINERAL FERTILIZATION N AND P}

In order to compare different mineral and organic fertilizers, source of nitrogen and phosphorus, trials were conducted in protected environment at Instituto Agronômico, in Campinas (SP), Brazil, from October to November, 2004 with rocket salad and at São João Farm, in Elias Fausto (SP), Brazil, from September 2004 to February 2005 with tomato. The treatments on the rocket salad trial were: four rate of $\mathrm{N}\left(0 ; 50 ; 100 ; 150 \mathrm{~kg} \mathrm{ha}^{-1} \mathrm{~N}\right)$ and four rate of $\mathrm{P}\left(0 ; 100 ; 200 ; 300 \mathrm{~kg}^{-1} \mathrm{P}_{2} \mathrm{O}_{5}\right)$ using the fertilizers MAP; DAP; hoof and horns flour (HHF) and bones flour (BF) at sowing and side dressing. Two experiments were conducted with tomato. Four rates of $\mathrm{N}$ on side dressing were studied $\left(0 ; 133 ; 266 ; 399 \mathrm{~kg} \mathrm{ha}^{-1} \mathrm{~N}\right)$

$\left(^{1}\right)$ Recebido para publicação em 23 de fevereiro de 2006 e aceito em 19 de fevereiro de 2009.

$\left({ }^{2}\right)$ Rua José Rodrigues Cardeal, 184, Centro, 13350-000 Elias Fausto (SP). E-mail: jr_cavallaro@yahoo.com.br

$\left({ }^{3}\right)$ Centro de Análise e Pesquisa Tecnológica do Agronegócio de Horticultura (IAC), Caixa Postal 28, 13012-970 Campinas (SP), E-mail: petrani@iac.sp.gov.br $\left(^{*}\right)$ Autor correspondente; fapassos@iac.sp.gov.br

$\left({ }^{4}\right)$ Av. Independência, 1402, 93010-003 São Leopoldo (RS), E-mail: jkneto@gmail.com

$\left({ }^{5}\right)$ UPD São Roque, Av. Três de Maio, 900, 18133-445 São Roque (SP). E-mail: tivelli@iac.sp.gov.br 
applying ammonium nitrate (AN) and HHF without change the rate of $\mathrm{P}$ at planting time. In a second trial, four rate of $\mathrm{P}$ were applied at planting time $\left(0 ; 250 ; 500 ; 750 \mathrm{~kg} \mathrm{ha}^{-1} \mathrm{P}_{2} \mathrm{O}_{5}\right)$ using triple superphosphate (TS) and $\mathrm{BF}$ without change of $\mathrm{N}$ (AN) rate on side dressing. The fertilization with $75 \mathrm{~kg} \mathrm{ha}^{-1} \mathrm{~N}$ and 300 $\mathrm{kg} \mathrm{ha}^{-1} \mathrm{P}_{2} \mathrm{O}_{5}$ using MAP + DAP at planting time and $75 \mathrm{~kg} \mathrm{ha}^{-1} \mathrm{~N}$ HHF on side dressing was the best treatment for rocket salad production. The organic fertilization with HHF was more efficacious when applied at planting time. The result showed that HHF was a better source of $\mathrm{N}$ than AN for tomato production and fruit average weight. The TS was a better source of $\mathrm{P}$ than the BF for tomato production.

Key words: Eruca sativa, Lycopersicum esculentum, hoof and horns flour, bones flour, $\mathrm{N}$ fertilization, $\mathrm{P}$ fertilization.

\section{INTRODUÇÃO}

Em 2007, eram cultivados no mundo aproximadamente 31 milhões de hectares certificados em agricultura orgânica. A Austrália tem-se mantido como detentora da maior área certificada de produção orgânica, com cerca de 12 milhões de hectares, enquanto a dos demais países tem sido muito alterada de um ano para outro (Willer e Minou, 2006; WiLleR e Minou, 2007). O Brasil está em sexto lugar, com área de 888 mil hectares, e poderá passar para o segundo lugar se forem considerados como orgânicos os 5 milhões de hectares de áreas com extrativismo, como considera os Ministérios do Meio Ambiente e da Agricultura, Pecuária e Abastecimento (WILler e Minou, 2006; Dias, 2007).

$\mathrm{Na}$ produção de alimentos orgânicos foram movimentados no Brasil, em 2007, algo em torno de 200 milhões a 250 milhões de dólares americanos. A expectativa é de aumento desse valor com a aprovação do Decreto 6.323, de 26/12/2007, com o qual é regulamentada a Lei $n^{\circ} .10 .831$ de 23/12/2003, em que são estabelecidas regras nacionais para a produção, certificação e comercialização de produtos orgânicos no Brasil.

O Estado de São Paulo se destaca como o principal produtor de hortaliças e o maior mercado consumidor no País. Em 2004, a área com cultivo orgânico de diferentes culturas neste Estado era correspondente a 10.235 ha. Destes, cerca de 900 ha eram cultivados com hortaliças no sistema orgânico (CAmARgo et al., 2006). Ainda segundo esses autores, a comercialização de produtos orgânicos no Brasil é o dobro da média mundial.

Assim, vem aumentando a demanda por informações da pesquisa científica sobre a utilização de fertilizantes orgânicos e organo-minerais como alternativa para serem minimizados os desequilíbrios ecológicos causados pela adubação intensiva de hortaliças com fertilizantes minerais muito solúveis. Esse aumento de demanda pode ser devido ao incentivo governamental à agricultura familiar, com o que é indiretamente proporcionada a procura em maior escala por informações sobre a utilização de insumos, como fertilizantes orgânicos e compostos orgânicos, muitas vezes obtidos ou produzidos nas pequenas propriedades agrícolas.

Em virtude da quantidade cada vez maior de resíduos orgânicos gerados pelas atividades humana e a industrial, o uso agronômico desse tipo de fertilizante como fonte de nutrientes às plantas e como condicionadores do solo, tem-se constituído em alternativa viável na preservação da qualidade ambiental (Melo e MARQues, 2000).

No Brasil, o potencial de uso de resíduos orgânicos em hortaliças é grande, em virtude das extensas áreas com seu cultivo. Os materiais orgânicos podem ainda melhorar a fertilidade do solo, sendo gerados benefícios também para a cultura posterior. Dentre os efeitos gerados pela sua adição destacamse o aumento do $\mathrm{pH}$ e da capacidade de troca de cátions (Mello e VitTi, 2002).

Com a utilização dos fertilizantes orgânicos pelo produtor agrícola são atendidos os seguintes objetivos do sistema de produção orgânico e sustentável proposto por KAMIYAMA (2005): incremento da atividade biológica do solo e manutenção ou aumento da fertilidade do solo em longo prazo. Com o surgimento, cada vez maior, de materiais orgânicos provenientes de resíduos de diferentes atividades, há necessidade de se estudarem seus efeitos no sistema solo-planta (MelLo e VitTI, 2002).

Os resíduos orgânicos oriundos do processamento e abate de bovinos, comercializados na forma de farinha de casco e chifres e farinha de ossos são fontes alternativas fornecedoras de nitrogênio (14\% $\mathrm{N})$ e de fósforo $\left(27 \%\right.$ de $\left.\mathrm{P}_{2} \mathrm{O}_{5}\right)$, respectivamente. Contudo, há necessidade de se avaliarem essas alternativas de adubação para hortaliças, como o tomate e a rúcula, em que são requeridos nutrientes prontamente disponíveis.

O objetivo do trabalho foi avaliar a eficácia de doses de nitrogênio e fósforo dos fertilizantes farinha de casco e chifres e farinha de ossos em comparação com os fertilizantes sulfato de amônio, nitrato de amônio, fosfato monoamônico (MAP), fosfato diamônico (DAP) e superfosfato triplo, para as 
culturas da rúcula (ciclo curto) e do tomate (ciclo longo).

\section{MATERIAL E MÉTODOS}

Foi utilizado solo Neossolo Litólico Distrófico típico, de textura média, A moderado, mesodistrófico hipoférrico, argila de atividade alta (EMBRAPA, 1999), procedente da Unidade de Pesquisa e Desenvolvimento da APTA - SAA, Tietê (SP). Este solo foi escolhido devido aos reduzidos teores em fósforo e em matéria orgânica. A densidade real (de partícula) é $2,64 \mathrm{~g} \mathrm{~cm}^{-3}$ e a densidade aparente do solo é $1,3 \mathrm{~g} \mathrm{~cm}^{-3}$. Foi coletada amostra da camada arável, transportada para Campinas e Elias Fausto (SP), onde se realizaram os experimentos, respectivamente, com rúcula e tomateiro, ambos sob cultivo protegido, e em vasos de $14 \mathrm{~L}$, com $28 \mathrm{~cm}$ de diâmetro, correspondendo a $0,06 \mathrm{~m}^{2}$ de área; cada vaso recebeu $10 \mathrm{~L}$ de solo peneirado em peneira de $5 \mathrm{~mm}$ para eliminação de torrões.

No experimento com rúcula, realizado no Centro Experimental Central, do Instituto Agronômico (IAC), foram estudados os fertilizantes minerais MAP (fosfato monoamônico) com $10 \%$ de $\mathrm{N}$ e $52 \%$ de $\mathrm{P}_{2} \mathrm{O}_{5}$, DAP (fosfato diamônico) com $17 \%$ de $\mathrm{N}$ e $44 \%$ de $\mathrm{P}_{2} \mathrm{O}_{5}$ e o sulfato de amônio com $20 \%$ de N.

Em dois experimentos com tomate, desenvolvidos no Sítio São João, foram estudados os fertilizantes minerais superfosfato triplo com $44 \%$ de $\mathrm{P}_{2} \mathrm{O}_{5}$ e o nitrato de amônio com $33 \%$ de $\mathrm{N}$.

Os fertilizantes orgânicos estudados nos experimentos com rúcula e tomate foram a farinha de casco e chifres como fonte de $\mathrm{N}$ e a farinha de ossos como fonte de $\mathrm{P}_{2} \mathrm{O}_{5}$, os quais foram analisados no Laboratório de Insumos da CATI/SAA, segundo método descrito em BRASIL (1983) e no Laboratório do Setor de Fertilidade de Solos do IAC, sendo avaliadas as seguintes composições:

a) Farinha de casco e chifres (FCC): $\mathrm{pH}$ : 7,03; $\mathrm{N}$ total: $14,43 \% ; \mathrm{P}_{2} \mathrm{O}_{5}$ solúvel em ácido cítrico a 2\%: $0,64 \% ; \mathrm{P}_{2} \mathrm{O}_{5}$ total: $0,60 \% ; \mathrm{K}_{2} \mathrm{O}$ total: $4,24 \%$; umidade $65^{\circ} \mathrm{C}$ : $10,74 \%$; matéria orgânica (perda ao rubro): $81,6 \%$; matéria orgânica na matéria seca: 91,4 $\%$; cálcio: $0,26 \%$; magnésio: $0,06 \%$; enxofre: $2,39 \%$; zinco: $115 \mathrm{mg} \mathrm{kg}^{-1}$; manganês: $23 \mathrm{mg} \mathrm{kg}^{-1}$; cobre: 12 $\mathrm{mg} \mathrm{kg}^{-1}$; ferro: $731 \mathrm{mg} \mathrm{kg}^{-1}$; B (água quente): 0,9 mg $\mathrm{kg}^{-1}$. Relação $\mathrm{C} / \mathrm{N}$ total: 3,50.

Análise granulométrica: material que passa na peneira 10 : $97,8 \%$; na peneira $20: 97,4 \%$; e na peneira 50: $78,3 \%$.

b) Farinha de ossos (FO): $\mathrm{pH}: 7,72 ; \mathrm{N}$ total: $4,08 \% ; \mathrm{P}_{2} \mathrm{O}_{5}$ solúvel em ácido cítrico a $2 \%: 24,82 \% ; \mathrm{P}_{2} \mathrm{O}_{5}$ total: $27,26 \% ; \mathrm{K}_{2} \mathrm{O}$ total: $4,33 \%$; umidade $65^{\circ} \mathrm{C}: 5,84 \%$; matéria orgânica (perda ao rubro): 27,68\%; matéria orgânica na matéria seca: $29,40 \%$; cálcio: $23,26 \%$; magnésio: $0,39 \%$; enxofre: não detectado pelo método; zinco: $18 \mathrm{mg} \mathrm{kg}^{-1}$; manganês: $2 \mathrm{mg} \mathrm{kg}^{-1}$; cobre: $2 \mathrm{mg}$ $\mathrm{kg}^{-1}$; ferro: $11 \mathrm{mg} \mathrm{kg}^{-1}$; B (água quente): $0,4 \mathrm{mg} \mathrm{kg}^{-1}$. Relação C/N total: 4,0.

Análise granulométrica: material que passa na peneira 10: $99,9 \%$; na peneira $20: 99,4 \%$; e na peneira 50: $88,3 \%$.

O delineamento experimental adotado foi o de blocos ao acaso com 16 tratamentos e cinco repetições, sendo cada dois vasos representativos de um parcela, no total de 160 vasos. A disposição dos blocos foi em cinco linhas duplas, com 16 vasos em cada linha, representativos dos tratamentos, sendo 32 vasos por bloco. Foram constituídos cinco grupos abrangendose 15 tratamentos, além da testemunha absoluta. Os tratamentos do experimento com rúcula foram os constantes da tabela 1.

Visando à correção da acidez do solo e ao fornecimento de $\mathrm{Ca}$ e $\mathrm{Mg}$ às plantas, foi aplicado, aos trinta dias antes da semeadura da rúcula, calcário dolomítico calcinado, (PRNT=100\%) na dose de $10 \mathrm{~g}$ por vaso, correspondente a $1,7 \mathrm{t} \mathrm{ha}^{-1}$. Para complementar o suprimento de Ca e $\mathrm{S}$, aplicaram-se, em todos os tratamentos, 2,7 g de gesso agrícola por vaso, correspondente a $450 \mathrm{~kg} \mathrm{ha}^{-1}$, também aos trinta dias antes da semeadura da cultura. Visando ao suprimento de potássio em todos os tratamentos, foi aplicado $1 \mathrm{~g}$ de sulfato de potássio por vaso, correspondente a $84 \mathrm{~kg} \mathrm{ha}^{-1}$ de $\mathrm{K}_{2} \mathrm{O}$, aos quinze dias antes da semeadura da cultura. A calagem e adubação citadas foram baseadas em TRANI et al. (1997b).

A semeadura direta da cultura da rúcula cv. Cultivada foi feita aos 25 de outubro de 2004, após dois dias de realizada capina manual e nivelamento e destorroamento do solo superficial nos vasos, visando à não-interferência no processo de germinação das sementes. A irrigação das plantas foi realizada com regador, mantendo-se a mesma quantidade de água por vaso, em cada rega diária. Uma semana após a semeadura, realizou-se o desbaste, deixando-se 30 plantas por vaso. As adubações em cobertura de todos os tratamentos foram parceladas em duas vezes, sendo a primeira aos 11 dias e a segunda aos 21 dias após a semeadura da cultura. Semanalmente, foram realizadas leituras de contagem do número de folhas por planta e de altura de plantas, em cinco plantas por parcela, com uma régua graduada em centímetros, desde o colo da planta até a extremidade da folha mais comprida esticada. 
Tabela 1. Tratamentos constituídos de doses de $\mathrm{N}$ e $\mathrm{P}_{2} \mathrm{O}_{5}\left(\mathrm{~kg} \mathrm{ha}^{-1}\right)$ de adubos minerais e orgânicos, em diferentes períodos de aplicação (pré-semeadura e cobertura) em rúcula sob cultivo protegido, em Campinas (SP), 2004

\begin{tabular}{|c|c|c|c|c|c|c|}
\hline \multirow{2}{*}{ Tratamento } & \multicolumn{4}{|c|}{ Fertilização em pré-semeadura } & \multicolumn{2}{|c|}{ Fertilização em cobertura } \\
\hline & $\mathrm{N}$ & Fonte & $\mathrm{P}_{2} \mathrm{O}_{5}$ & Fonte & $\mathrm{N}$ & Fonte \\
\hline & 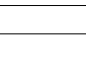 & 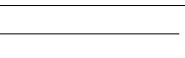 & & $\bar{z}$ & 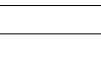 & \\
\hline $\mathrm{T} 1$ & 25 & FCC & 100 & FO & 75 & FCC \\
\hline T2 & 50 & FCC & 200 & $\mathrm{FO}$ & 75 & FCC \\
\hline $\mathrm{T} 3$ & 75 & FCC & 300 & $\mathrm{FO}$ & 75 & $\mathrm{FCC}$ \\
\hline $\mathrm{T} 4$ & 25 & $\mathrm{MAP}+\mathrm{DAP}$ & 100 & MAP+DAP & 75 & FCC \\
\hline T5 & 50 & $\mathrm{MAP}+\mathrm{DAP}$ & 200 & $\mathrm{MAP}+\mathrm{DAP}$ & 75 & FCC \\
\hline T6 & 75 & $\mathrm{MAP}+\mathrm{DAP}$ & 300 & $\mathrm{MAP}+\mathrm{DAP}$ & 75 & $\mathrm{FCC}$ \\
\hline T7 & - & - & 300 & FO & 50 & SA \\
\hline $\mathrm{T} 8$ & - & - & 300 & FO & 100 & SA \\
\hline T9 & - & - & 300 & FO & 150 & SA \\
\hline $\mathrm{T} 10$ & - & - & 300 & FO & 50 & FCC \\
\hline $\mathrm{T} 11$ & - & - & 300 & FO & 100 & $\mathrm{FCC}$ \\
\hline T12 & - & - & 300 & $\mathrm{FO}$ & 150 & FCC \\
\hline $\mathrm{T} 13$ & 50 & FCC & 300 & FO & - & - \\
\hline T14 & 100 & FCC & 300 & FO & - & - \\
\hline T15 & 150 & FCC & 300 & FO & - & - \\
\hline $\mathrm{T} 16^{(1)}$ & - & - & - & - & - & - \\
\hline
\end{tabular}

FCC: farinha de casco e chifres $(14 \% \mathrm{~N})$; FO: farinha de ossos $\left(27 \% \mathrm{P}_{2} \mathrm{O}_{5}\right)$; MAP: fosfato monoamônico $\left(10 \% \mathrm{~N}\right.$ e $52 \%$ P $\left.\mathrm{O}_{5}\right)$; DAP: fosfato diamônico $\left(17 \% \mathrm{~N}\right.$ e $\left.44 \% \mathrm{P}_{2} \mathrm{O}_{5}\right)$; $\mathrm{SA}$ : sulfato de amônio $(20 \% \mathrm{~N})$.

$\left.{ }^{1}\right)$ Testemunha absoluta, sem aplicação de nitrogênio e fósforo.

A colheita da rúcula foi realizada aos 31 dias após sua semeadura, cortando-se as raízes e coletandose as partes aéreas das plantas, que foram imediatamente acondicionadas em sacos plásticos, e, em seguida, em caixa térmica de poliestireno expandido para manutenção da turgescência das folhas. Ao término da colheita, todo o material colhido foi mantido em refrigerador. Foram determinadas as quantidades das massas de matéria fresca e seca da parte aérea, em gramas, e a área foliar, $\mathrm{em}^{2}{ }^{2}$ por metro quadrado cultivado de rúcula. A quantidade de matéria seca foi determinada após secagem em estufa elétrica a $65-70^{\circ} \mathrm{C}$ até massa constante e a área foliar em integrador de área foliar.

Os dados relativos à rúcula foram submetidos ao teste de Hartley para verificação da homocedasticidade e, devido à homogeneidade entre as variâncias dos tratamentos, não houve necessidade de transformação (NogUeIRA, 1991). Os dados foram submetidos à análise da variância com teste $\mathrm{F}$ e as médias comparadas por meio de contrastes ortogonais com teste $\mathrm{t}$ ( 5 e $1 \%$ de probabilidade), conforme descrito em Nogueira (1991).
Com a cultura do tomateiro, foram realizados dois experimentos de adubação orgânica e mineral com $\mathrm{N}$ e P. Os tratamentos foram dispostos em blocos ao acaso com quatro repetições, em esquema fatorial ( 2 fertilizantes $\times 4$ doses), com tratamento adicional (testemunha absoluta).

No primeiro experimento foram avaliados o efeito do nitrato de amônio (NA) e da farinha de casco e chifres (FCC) em quatro aplicações, aos 15 dias antes do transplante das mudas e das outras três doses, em cobertura aos 30,60 e 90 dias após o transplante das mudas. Em todos os tratamentos, utilizou-se uma dose fixa e única de superfosfato triplo aos 10 dias antes do transplante das mudas. $\mathrm{Na}$ tabela 2 estão relacionados os tratamentos utilizados.

No segundo experimento, avaliou-se o efeito de três doses de superfosfato triplo (ST) e o de farinha de ossos (FO), incorporadas ao solo aos 10 dias antes do transplante das mudas, com uma dose fixa de nitrato de amônio em cobertura, parcelada em três aplicações, conforme apresentado na tabela 3 . 
Tabela 2. Tratamentos de experimento em tomateiro, constituídos por quatro doses de nitrato de amônio e farinha de casco e chifres, aplicados em cobertura. Elias Fausto (SP), 2004/2005

\begin{tabular}{|c|c|c|c|c|}
\hline \multirow{2}{*}{ Tratamento } & \multicolumn{2}{|c|}{ Fertilização em pré-transplante } & \multicolumn{2}{|c|}{ Fertilização em cobertura ${ }^{(1)}$} \\
\hline & $\mathrm{P}_{2} \mathrm{O}_{5}$ & Fonte & $\mathrm{N}$ & Fonte \\
\hline & 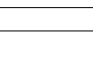 & 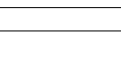 & 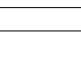 & 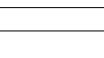 \\
\hline $\mathrm{T} 1$ & 0 & ST & 0 & - \\
\hline $\mathrm{T} 2$ & 750 & ST & 0 & - \\
\hline $\mathrm{T} 3$ & 750 & ST & 133 & NA \\
\hline $\mathrm{T} 4$ & 750 & ST & 266 & NA \\
\hline T5 & 750 & ST & 399 & NA \\
\hline T6 & 750 & ST & 133 & FCC \\
\hline $\mathrm{T} 7$ & 750 & ST & 266 & $\mathrm{FCC}$ \\
\hline $\mathrm{T} 8$ & 750 & ST & 399 & FCC \\
\hline
\end{tabular}

$\left({ }^{1}\right)$ Doses de $\mathrm{N}$ em quatro aplicações, a primeira aos 15 dias antes do transplante das mudas realizado em 6/10/2004 e as demais a cada 30 dias, a partir de 6/11/2004. ST: superfosfato triplo $\left(44 \% \mathrm{P}_{2} \mathrm{O}_{5}\right)$ aplicado aos 10 dias antes do transplante das mudas; NA: nitrato de amônio $(33 \% \mathrm{~N})$; FCC: farinha de casco e chifres $(14 \% \mathrm{~N})$.

Tabela 3. Tratamentos de experimento com o tomateiro, constituídos por três doses de superfosfato triplo e farinha de ossos aplicados em pré-transplante ${ }^{(1)}$. Elias Fausto (SP), 2004/2005

\begin{tabular}{|c|c|c|c|c|}
\hline \multirow{2}{*}{ Tratamento } & \multicolumn{2}{|c|}{ Fertilização em pré-transplante } & \multicolumn{2}{|c|}{ Fertilização em cobertura $\left(\mathrm{kg} \mathrm{ha}^{-1}\right)$} \\
\hline & $\mathrm{P}_{2} \mathrm{O}_{5}$ & Fonte & $\mathrm{N}$ & Fonte \\
\hline & 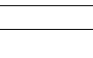 & 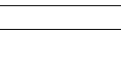 & 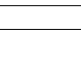 & \\
\hline $\mathrm{T} 1$ & 0 & - & 0 & NA \\
\hline $\mathrm{T} 2$ & 0 & - & 399 & NA \\
\hline T3 & 250 & ST & 399 & NA \\
\hline $\mathrm{T} 4$ & 500 & ST & 399 & NA \\
\hline T5 & 750 & ST & 399 & NA \\
\hline T6 & 250 & $\mathrm{FO}$ & 399 & NA \\
\hline $\mathrm{T} 7$ & 500 & FO & 399 & NA \\
\hline $\mathrm{T} 8$ & 750 & FO & 399 & NA \\
\hline
\end{tabular}

(1) Aplicação dos adubos fosfatados aos 10 dias antes do plantio das mudas; NA: nitrato de amônio (33\% N) em quatro aplicações, a primeira aos 15 dias antes do transplante das mudas, realizado em 6/10/2004 e, as demais, a cada 30 dias, iniciando-se em 6/11/2004; ST: superfosfato triplo $\left(44 \% \mathrm{P}_{2} \mathrm{O}_{5}\right)$; FO: farinha de ossos $\left(27 \% \mathrm{P}_{2} \mathrm{O}_{5}\right)$.

As parcelas constaram de nove vasos, cada um com uma planta. A irrigação nos vasos foi realizada no sistema de gotejamento, utilizando-se microtubos gotejadores. Os tratamentos fitossanitários foram aplicados durante o ciclo da cultura, adotandose as recomendações de Sinigaglia et al. (2000).

Em todos os tratamentos, inclusive na testemunha absoluta, foram realizadas calagem e gessagem, aos 30 dias antes do transplante das mudas, incorporando-se $10 \mathrm{~g}$ de calcário dolomítico calcinado Minercal (100\% de PRNT) e 2,7 g de gesso agrícola por vaso, correspondentes, respectivamente, a $1,7 \mathrm{t} \mathrm{ha}^{-1} \mathrm{de}$ calcário e $450 \mathrm{~kg} \mathrm{ha}^{-1}$ de gesso agrícola. Também foram aplicados $2 \mathrm{~g}$ de sulfato de potássio por vaso, equivalentes a $167 \mathrm{~kg} \mathrm{ha}^{-1}$ de $\mathrm{K}_{2} \mathrm{O}$, aos 15 dias antes do transplante das mudas. As quantidades aplicadas de calcário, de gesso e potássio foram baseadas em TRANI et al. (1997a). A semeadura do tomate híbrido Sheila, tipo salada, foi realizada previamente em bandejas de isopor de 128 células em 8/9/2004. Cada muda de tomate com quatro folhas definitivas foi transplantada para um vaso em $6 / 10 / 2004$, sendo conduzida em haste única e amarrada por fitilhos de plástico. 
Os vasos foram dispostos em linhas duplas dentro das estufas no espaçamento de $0,45 \mathrm{~m} \times$ $0,45 \mathrm{~m}$ entre vasos e $1,10 \mathrm{~m}$ entre linhas duplas. As doses de $\mathrm{N}$ de 0,$8 ; 1,6$; e $2,4 \mathrm{~g}$ de $\mathrm{N}$ por vaso foram correspondentes a 133 ; 266 ; e $399 \mathrm{~kg} \mathrm{ha}^{-1}$ de $\mathrm{N}$ e as doses de $\mathrm{P}, 1,5 ; 3,0$; e $4,5 \mathrm{~g}$ de $\mathrm{P}_{2} \mathrm{O}_{5}$, correspondentes a 250; 500 ; e $750 \mathrm{~kg} \mathrm{ha}^{-1}$ de $\mathrm{P}_{2} \mathrm{O}_{5}$. Foram realizadas oito colheitas quando os frutos estavam maduros, a cada oito dias, iniciando-se em $1 .^{\circ} / 12 / 2004$ e encerrando-se em $1 .^{\circ} / 2 / 2005$. Foram realizadas avaliações quanto à produtividade, número de frutos por planta e à massa média do fruto de tomate.

Para o tomateiro também foi verificada homogeneidade das variâncias, não sendo necessária a transformação dos dados. Tais dados foram submetidos à análise de variância com teste F. As médias dos tratamentos foram comparadas pelo teste de Tukey ( $5 \%$ de probabilidade).

\section{RESULTADOS E DISCUSSÃO}

\section{Rúcula}

As médias obtidas para as quatro variáveis estudadas estão apresentadas na tabela 4, e os valores dos contrastes e suas significâncias estão na Tabela 5 .

Houve efeito positivo da adubação para as quatro variáveis estudadas (contraste $n .^{\circ} 1$ - Tabela 5). O efeito da adubação orgânica exclusivamente na pré-semeadura foi significativamente maior ao da adubação orgânica aplicada na pré-semeadura e em cobertura, para as quatro variáveis (contraste n. $^{\circ} 2$ Tabela 5). Sendo a rúcula uma hortaliça de ciclo curto (30 a 35 dias) e, com a aplicação do fertilizante orgânico aos 10 dias antes da semeadura, houve mais tempo para a mineralização e o fornecimento de nitrogênio às plantas.

Tabela 4. Altura de plantas, quantidade de massa de matéria fresca (MMFPA) e seca (MMSPA) da parte aérea e área foliar (AF) de rúcula. Campinas (SP), 2004

\begin{tabular}{lcccc}
\hline Tratamentos ${ }^{(1)}$ & Altura das plantas & MMFPA & MMSPA & AF \\
\cline { 2 - 4 } T1 & $\mathrm{cm}$ & 2077,5 & $\mathrm{~cm}^{2}$ \\
T2 & 20,64 & 2009,2 & 334,4 & 39951,3 \\
T3 & 21,30 & 2199,1 & 325,2 & 38922,8 \\
T4 & 21,30 & 2239,1 & 337,3 & 42632,7 \\
T5 & 22,08 & 2530,7 & 344,9 & 43487,3 \\
T6 & 20,70 & 2627,3 & 371,2 & 50390,7 \\
T7 & 22,24 & 2054,2 & 363,0 & 52527,8 \\
T8 & 19,54 & 317,2 & 39590,5 \\
T9 & 20,84 & 264,1 & 435,2 & 42967,5 \\
T10 & 20,82 & 337,7 & 40877,6 \\
T11 & 20,08 & 1666,0 & 289,5 & 37997,3 \\
T12 & 20,74 & 1661,0 & 286,6 & 32119,2 \\
T13 & 18,64 & 310,3 & 36563,9 \\
T14 & 20,32 & 348,9 & 40789,5 \\
T15 & 21,04 & 343,1 & 43572,6 \\
T16 & 21,98 & 346,9 & 43438,7 \\
\hline
\end{tabular}

(1) Tratamentos:

T1, T2 e T3: três doses de FCC $\left(25 ; 50 ; 75 \mathrm{~kg} \mathrm{ha}^{-1}\right.$ de N) e FO $\left(100 ; 200 ; 300 \mathrm{~kg} \mathrm{ha}^{-1}\right.$ de $\left.\mathrm{P}_{2} \mathrm{O}_{5}\right)$ na pré-semeadura e dose única de FCC $(75 \mathrm{~kg}$ ha ${ }^{-1}$ de N) em cobertura.

T4, T5 e T6: três doses de DAP + MAP $\left(25 ; 50 ; 75 \mathrm{~kg} \mathrm{ha}^{-1}\right.$ de $\mathrm{N}+100 ; 200 ; 300 \mathrm{~kg} \mathrm{ha}^{-1}$ de $\left.\mathrm{P}_{2} \mathrm{O}_{5}\right)$ na pré-semeadura e dose única de FCC (75 $\mathrm{kg} \mathrm{ha}^{-1}$ de N) em cobertura.

T7, T8 e T9: dose única de farinha de ossos $\left(300 \mathrm{~kg} \mathrm{ha}^{-1}\right.$ de $\left.\mathrm{P}_{2} \mathrm{O}_{5}\right)$ na pré-semeadura e três doses de sulfato de amônio (50; $100 ; 150 \mathrm{~kg}$ ha ${ }^{-1}$ de N) em cobertura.

T10, T11 e T12: dose única de farinha de ossos $\left(300 \mathrm{~kg} \mathrm{ha}^{-1}\right.$ de $\left.\mathrm{P}_{2} \mathrm{O}_{5}\right)$ na pré-semeadura e três doses de farinha de casco e chifres $(50 ; 100$; 150 $\mathrm{kg}_{\mathrm{h}} \mathrm{a}^{-1} \mathrm{de} \mathrm{N}$ ) em cobertura.

T13, T14 e T15: dose única de farinha de ossos $\left(300 \mathrm{~kg} \mathrm{ha}^{-1}\right.$ de $\left.\mathrm{P}_{2} \mathrm{O}_{5}\right)$ na pré-semeadura e três doses de farinha de casco e chifres $(50 ; 100 ; 150$ $\mathrm{kg} \mathrm{ha}^{-1}$ de N) na pré-semeadura.

T16: testemunha absoluta, sem aplicação de $\mathrm{N}$ e P. 
Tabela 5. Valores de contrastes e suas significâncias pelo teste t para altura das plantas, quantidades de matéria fresca (MMFPA) e seca (MMSPA) da parte aérea e área foliar (AF) de rúcula. Campinas (SP), 2004

\begin{tabular}{|c|c|c|c|c|}
\hline Contraste $^{(1)}$ & Altura das plantas & MMFPA & MMSPA & $\mathrm{AF}$ \\
\hline $\mathrm{N} \cdot{ }^{\circ}$ & $\mathrm{cm}$ & 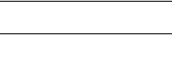 & 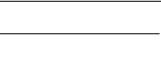 & $\mathrm{cm}^{2}$ \\
\hline 1 & $100,16^{* *}$ & $16043,6^{* *}$ & $1211,2^{* *}$ & $291931,9^{* *}$ \\
\hline 2 & $3,88^{* *}$ & $1487,7^{* *}$ & $152,4^{* *}$ & $21120,4^{* *}$ \\
\hline 3 & $-1,78^{* *}$ & $-1111,2^{* *}$ & $-82,1^{* *}$ & $-24899,0^{* *}$ \\
\hline 4 & $0,66^{*}$ & $121,6^{\mathrm{ns}}$ & $2,7^{\mathrm{ns}}$ & $2681,3^{\mathrm{ns}}$ \\
\hline 5 & $0,16^{\mathrm{ns}}$ & $388,2^{*}$ & $18,1^{\mathrm{ns}}$ & $9040,5^{* *}$ \\
\hline 6 & $1,28^{* *}$ & $85,0^{\mathrm{ns}}$ & $20,4^{\mathrm{ns}}$ & $1287,1^{\mathrm{ns}}$ \\
\hline 7 & $-1,44^{* *}$ & $11,7^{\mathrm{ns}}$ & $20,7^{\mathrm{ns}}$ & $-1433,4^{\mathrm{ns}}$ \\
\hline 8 & $1,66^{* *}$ & $131,6^{\mathrm{ns}}$ & $-2,0^{\mathrm{ns}}$ & $2649,1^{\mathrm{ns}}$ \\
\hline $\mathrm{F}(\text { contrastes })^{(2)}$ & $74,0^{* *}$ & $12,57^{* *}$ & $6,69^{* *}$ & $10,49 * *$ \\
\hline $\mathrm{CV}(\%)$ & 2,42 & 11,80 & 8,10 & 11,71 \\
\hline
\end{tabular}

$\left({ }^{1}\right) \mathrm{N} .{ }^{\mathrm{o}} 1$ (efeito da adubação) $=(\mathrm{T} 1+\mathrm{T} 2+\mathrm{T} 3+\mathrm{T} 4+\mathrm{T} 5+\mathrm{T} 6+\mathrm{T} 7+\mathrm{T} 8+\mathrm{T} 9+\mathrm{T} 10+\mathrm{T} 11++\mathrm{T} 12+\mathrm{T} 13+\mathrm{T} 14+\mathrm{T} 15)-15 . \mathrm{T} 16$;

N. ${ }^{\circ} 2$ (adubação orgânica exclusivamente na pré-semeadura versus na pré-semeadura e cobertura) $=(\mathrm{T} 13+\mathrm{T} 14+\mathrm{T} 15)-(\mathrm{T} 10+\mathrm{T} 11+\mathrm{T} 12)$;

$\mathrm{N} .{ }^{\circ} 3$ (fonte de adubação de pré-plantio $)=(\mathrm{T} 1+\mathrm{T} 2+\mathrm{T} 3)-(\mathrm{T} 4+\mathrm{T} 5+\mathrm{T} 6)$;

$\mathrm{N}^{\circ} 4$ (efeito de dose dentro dos tratamentos $\mathrm{T} 1$ e $\left.\mathrm{T} 3\right)=\mathrm{T} 3-\mathrm{T} 1$;

N. ${ }^{\circ} 5$ (efeito de dose dentro dos tratamentos $\mathrm{T} 4$ e T6) $=\mathrm{T} 6-\mathrm{T} 4$;

N. ${ }^{\circ} 6$ (efeito de dose dentro dos tratamentos T7 e T9) = T9 - T7;

N. ${ }^{\circ} 7$ (efeito de dose dentro dos tratamentos $\mathrm{T} 10$ e T12) = T12 $-\mathrm{T} 10$;

N. ${ }^{\circ} 8$ (efeito de dose dentro dos tratamentos T13 e T15) = T15 - T13;

$\left({ }^{2}\right) * *$ Significativos a $1 \%$ de probabilidade.

A rápida mineralização da matéria orgânica pode ser decorrente da estreita relação $\mathrm{C} / \mathrm{N}(3,5: 1)$ da farinha de casco e chifres. Esse resultado é concordante com observação de CATANI et al. (1956) e relatos de KIEHL (1985) para os fertilizantes orgânicos com o $\mathrm{N}$ na forma de proteina. A aplicação de FCC aos 10 dias antes da semeadura da rúcula foi feita conforme estudos de PRADO (1941) ${ }^{(6)}$ e recomendações de TRANi et al. (1997b). Produtos de origem animal (FCC, farinha de peixes e farinha de sangue) de baixa relação $\mathrm{C} / \mathrm{N}(<$ $10 / 1$ ) são rapidamente mineralizados quanto ao $\mathrm{N}$. LABER (2003), avaliando diversos adubos orgânicos de origem vegetal e animal para hortaliças, verificou ser a farinha de casco e chifres um dos mais eficazes quanto à velocidade de liberação do nitrogênio para absorção pelas plantas. EsPíNDOLA FILHO (1998) verificou rápida assimilação de nitrogênio pela catalonha e pelo almeirão, quando foram utilizados resíduos de pescado marinho como fertilizante orgânico, aplicados aos sete dias antes do plantio. O almeirão e a catalonha são hortaliças de ciclo similar ao da rúcula (30 a 40 dias entre a semeadura e a colheita).

$\left.{ }^{6}\right)$ PRADO, O.T. Relatório dos Anos Agrícolas 1938-1940. Campinas: Instituto Agronômico do Estado de São Paulo, 1941. Paginação irregular. (Datilografado e encadernado)
Quanto à fonte de adubação da pré-semeadura, a exclusivamente orgânica (farinha de ossos e farinha de casco e chifres) foi inferior à exclusivamente mineral (DAP e MAP) para as quatro variáveis (contraste n. ${ }^{\circ} 3$ - Tabela 5). Dentre os tratamentos em que se utilizaram FCC e FO na pré-semeadura, com FCC em cobertura, a dose maior foi diferente da menor e superior apenas para altura das plantas, (contraste n. ${ }^{\circ} 4$ - Tabela 5). Ressalte-se que a altura da rúcula é um parâmetro importante, quando da escolha desta hortaliça folhosa pelo consumidor. A rúcula é comercializada em maços, em que é mais importante o tamanho das folhas do que sua massa fresca.

Dentre os tratamentos com DAP e MAP na présemeadura, com FCC em cobertura, a dose maior foi diferente da menor e superior para a quantidade de massa da matéria fresca da parte aérea e área foliar (contraste n. ${ }^{\circ} 5$ - Tabela 5). Dentre os tratamentos em que foi aplicado FO na pré-semeadura, com três doses de sulfato de amônio em cobertura, a dose maior foi diferente da menor e superior apenas para a altura das plantas, (contraste $\mathrm{n}^{\circ} 6$ - Tabela 5).

Dentre os tratamentos em que se utilizou FO na pré-semeadura, com três doses de FCC em cobertura, a dose maior foi diferente da menor e inferior apenas para a altura das plantas (contraste $\mathrm{n}^{\circ} \mathrm{7}$ - Tabela 5). 
Dentre os tratamentos com FO e FCC em três doses apenas na pré-semeadura, a dose maior foi diferente da menor e superior apenas para a altura das plantas (contraste n. ${ }^{\circ} 8$ - Tabela 5).

Pelos resultados, pode-se dizer que houve efeito positivo tanto da adubação mineral quanto da adubação orgânica na produtividade da rúcula. A adubação mineral na pré-semeadura foi superior à orgânica, ambas com adubação orgânica em cobertura, com efeito benéfico da dose maior em relação à menor na quantidade de massa de matéria fresca da parte aérea e na área foliar. Quanto à adubação orgânica, verificou-se que é melhor aplicar a farinha de casco e chifres na pré-semeadura juntamente com a farinha de ossos, sendo a dose maior diferente da menor apenas para a altura das plantas, não havendo influência nas quantidades de matéria fresca e seca da parte aérea e na área foliar. O tratamento superior para o tipo de solo em estudo é correspondente à dose 3 de DAP + MAP na pré-semeadura com uma dose fixa de FCC em cobertura $\left(75 \mathrm{~kg} \mathrm{ha}^{-1} \mathrm{~N}+300 \mathrm{~kg} \mathrm{ha}^{-1}\right.$ $\mathrm{P}_{2} \mathrm{O}_{5}$ em pré-semeadura e $75 \mathrm{~kg} \mathrm{ha}^{-1} \mathrm{~N}$ em cobertura). Para o cultivo de rúcula nesse sistema orgânico de produção, o tratamento mais eficaz foi a dose 1 de FO e FCC na pré-semeadura, sem cobertura $\left(300 \mathrm{~kg} \mathrm{ha}^{-1}\right.$ $\mathrm{P}_{2} \mathrm{O}_{5}+100 \mathrm{~kg} \mathrm{ha}^{-1} \mathrm{~N}$ ). Não foram constatados na literatura nacional e internacional relatos de pesquisas com fertilizantes à base de farinha de casco e chifre e farinha de ossos e sua ação na produção de rúcula, tanto isoladamente como em comparação com os fertilizantes minerais DAP e MAP.

\section{Tomate}

Na tabela 6, estão apresentadas as médias dos tratamentos para produção, número de frutos por planta e massa média de frutos, conforme diferentes doses de nitrato de amônio e farinha de casco e chifres, aplicados em cobertura, com dose única e fixa de fósforo na forma de superfosfato triplo aos 10 dias antes do transplante das mudas, além da testemunha absoluta sem $\mathrm{P}$ e sem $\mathrm{N}$.

Verificou-se efeito positivo e significativo da adubação nitrogenada com farinha de casco e chifres para a produção e massa média dos frutos, em relação à testemunha absoluta e ao tratamento sem adubação nitrogenada. Também não se constatou o efeito do nitrogênio mineral em relação à dose zero de nitrogênio para as três variáveis estudadas. Por outro lado, não se verificou diferença significativa entre o tratamento com a menor dose de nitrato de amônio e as doses de farinha de casco e chifres para produção e número de frutos por planta.

Tabela 6. Produtividade, número de frutos por planta e massa média de frutos de tomateiro em experimento com adubo orgânico (farinha de casco e chifres) e mineral (nitrato de amônio), aplicados em cobertura, Elias Fausto, SP, $2004 / 2005$.

\begin{tabular}{lccr}
\hline Tratamentos $^{1}$ & Produtividade & Frutos por planta & Massa média dos frutos \\
\hline T1 & kg planta ${ }^{-1}$ & Número & $(\mathrm{g})$ \\
T2 & $2,105 \mathrm{~d}$ & $23,22 \mathrm{c}$ & $90 \mathrm{~d}$ \\
T3 & $2,680 \mathrm{~cd}$ & $28,36 \mathrm{bc}$ & $94 \mathrm{~d}$ \\
T4 & $3,470 \mathrm{abc}$ & $34,70 \mathrm{ab}$ & $100 \mathrm{bcd}$ \\
T5 & $3,028 \mathrm{bc}$ & $31,97 \mathrm{ab}$ & $95 \mathrm{~cd}$ \\
T6 & $2,738 \mathrm{~cd}$ & $29,11 \mathrm{abc}$ & $94 \mathrm{~d}$ \\
T7 & $3,708 \mathrm{ab}$ & $35,33 \mathrm{ab}$ & $106 \mathrm{abc}$ \\
T8 & $4,125 \mathrm{a}$ & $36,39 \mathrm{a}$ & $114 \mathrm{a}$ \\
F $($ tratamentos) & $3,985 \mathrm{a}$ & $36,50 \mathrm{a}$ & $109 \mathrm{ab}$ \\
DMS $(5 \%)^{3}$ & $16,940^{* *}$ & $7,97 * *$ & $12,372^{* *}$ \\
CV $(\%)$ & 0,817 & 7,95 & 11 \\
\hline
\end{tabular}

${ }^{1} \mathrm{~T} 1$ - Testemunha absoluta: $0 \mathrm{~kg} \mathrm{ha}^{-1} \mathrm{~N}$ e $0 \mathrm{~kg} \mathrm{ha}^{-1} \mathrm{P}_{2} \mathrm{O}_{5}$;

T2 - ST (superf. triplo): $750 \mathrm{~kg} \mathrm{ha}^{-1} \mathrm{P}_{2} \mathrm{O}_{5}$;

T3 - ST (superf. triplo): $750 \mathrm{~kg} \mathrm{ha}^{-1} \mathrm{P}_{2} \mathrm{O}_{5}$ e NA (nitrato de amônio): $133 \mathrm{~kg} \mathrm{ha}^{-1} \mathrm{~N}$;

T4 - ST (superf. triplo): $750 \mathrm{~kg} \mathrm{ha}^{-1} \mathrm{P}_{2} \mathrm{O}_{5}$ e NA (nitrato de amônio): $266 \mathrm{~kg} \mathrm{ha}^{-1} \mathrm{~N}$;

T5 - ST (superf. triplo): $750 \mathrm{~kg} \mathrm{ha}^{-1} \mathrm{P}_{2} \mathrm{O}_{5}$ e NA (nitrato de amônio): $399 \mathrm{~kg} \mathrm{ha}^{-1} \mathrm{~N}$;

T6 - ST (superf. triplo): $750 \mathrm{~kg} \mathrm{ha}^{-1} \mathrm{P}_{2} \mathrm{O}_{5}$ e FCC (far. de casco e chifres): $133 \mathrm{~kg} \mathrm{ha}^{-1} \mathrm{~N}$;

T7 - ST (superf. triplo): $750 \mathrm{~kg} \mathrm{ha}^{-1} \mathrm{P}_{2} \mathrm{O}_{5}$ e FCC (far. de casco e chifres): $266 \mathrm{~kg} \mathrm{ha}^{-1} \mathrm{~N}$;

T8 - ST (superf. triplo): $750 \mathrm{~kg} \mathrm{ha}^{-1} \mathrm{P}_{2} \mathrm{O}_{5}$ e FCC (far. de casco e chifres): $399 \mathrm{~kg} \mathrm{ha}^{-1} \mathrm{~N}$;

$2 * *$ significativo a $1 \%$ de probabilidade.

${ }^{3}$ DMS (5\%) : diferença mínima significativa a 5\% de probabilidade. 
Ainda verificou-se não haver diferença para número de frutos por planta, quando se compararam os fertilizantes minerais e orgânicos. Dentro de cada grupo de fertilizantes, orgânico e mineral, não houve efeito de doses dos nutrientes para todas as variáveis estudadas. Observou-se o efeito positivo da fonte orgânica (farinha de casco e chifres) nas variáveis estudadas.

Na tabela 7 estão apresentadas as médias dos tratamentos para produção, número de frutos por planta e massa média de frutos, conforme diferentes doses de superfosfato triplo e farinha de ossos aplicadas em pré-plantio, na dose fixa de nitrogênio em cobertura, na forma de nitrato de amônio, além da testemunha absoluta, sem $\mathrm{P}$ e sem $\mathrm{N}$.

Verificou-se efeito significativo da adubação fosfatada de ambas as fontes (farinha de ossos e superfosfato triplo) apenas para massa média dos frutos, exceto para a dose maior de farinha de ossos.

Tabela 7. Produtividade do tomateiro, números de frutos por planta e massa média dos frutos em experimento com adubo orgânico (farinha de ossos) e adubo mineral (superfosfato triplo) aplicados em pré-plantio. Elias Fausto, SP, $2004 / 2005$.

\begin{tabular}{|c|c|c|c|}
\hline Tratamentos $^{1}$ & Produtividade & Frutos por planta & Massa média dos frutos \\
\hline & kg planta $^{-1}$ & Número & (g) \\
\hline $\mathrm{T} 1$ & $2,295 \mathrm{~b}$ & $24,78 \mathrm{~b}$ & $93 \mathrm{c}$ \\
\hline $\mathrm{T} 2$ & $2,810 \mathrm{ab}$ & $29,00 \mathrm{ab}$ & $97 \mathrm{bc}$ \\
\hline T3 & $3,265 \mathrm{a}$ & $29,86 \mathrm{ab}$ & $110 \mathrm{a}$ \\
\hline $\mathrm{T} 4$ & $3,508 \mathrm{a}$ & $33,22 \mathrm{a}$ & 106 a \\
\hline T5 & $3,428 \mathrm{a}$ & $31,94 \mathrm{ab}$ & $107 \mathrm{a}$ \\
\hline T6 & $3,100 \mathrm{ab}$ & $28,94 \mathrm{ab}$ & $107 \mathrm{a}$ \\
\hline $\mathrm{T} 7$ & $3,165 \mathrm{a}$ & $28,75 \mathrm{ab}$ & $110 \mathrm{a}$ \\
\hline $\mathrm{T} 8$ & $2,840 \mathrm{ab}$ & $27,89 \mathrm{ab}$ & $102 \mathrm{ab}$ \\
\hline $\mathrm{F}(\text { tratamentos })^{2}$ & $4,861^{* *}$ & $2,70 *$ & $12,473^{* *}$ \\
\hline DMS $(5 \%)^{3}$ & 0,848 & 7,38 & 8 \\
\hline CV (\%) & 11,7 & 10,6 & 3,4 \\
\hline
\end{tabular}

\footnotetext{
${ }^{1} \mathrm{~T} 1$ - Testemunha absoluta: $0 \mathrm{~kg} \mathrm{ha}^{-1} \mathrm{~N}$ e $0 \mathrm{~kg} \mathrm{ha}^{-1} \mathrm{P}_{2} \mathrm{O}_{5}$;

T2 - NA (nitrato de amônio): $2,4 \mathrm{~g} \mathrm{~N}$ vaso $^{-1}$;

T3 - ST (superf. triplo): $250 \mathrm{~kg} \mathrm{ha}^{-1} \mathrm{P}_{2} \mathrm{O}_{5}$ e NA (nitrato de amônio): $399 \mathrm{~kg} \mathrm{ha}^{-1} \mathrm{~N}$;

T4 - ST (superf. triplo): $500 \mathrm{~kg} \mathrm{ha}^{-1} \mathrm{P}_{2} \mathrm{O}_{5}$ e NA (nitrato de amônio): $399 \mathrm{~kg} \mathrm{ha}^{-1} \mathrm{~N}$;

T5 - ST (superf. triplo): $750 \mathrm{~kg} \mathrm{ha}^{-1} \mathrm{P}_{2} \mathrm{O}_{5}$ e NA (nitrato de amônio): $399 \mathrm{~kg} \mathrm{ha}^{-1} \mathrm{~N}$;

T6 - FO (farinha de ossos): $250 \mathrm{~kg} \mathrm{ha}^{-1} \mathrm{P}_{2} \mathrm{O}_{5}$ e NA (nitrato de amônio): $399 \mathrm{~kg} \mathrm{ha}^{-1} \mathrm{~N}$;

T7 - FO (farinha de ossos): $500 \mathrm{~kg} \mathrm{ha}^{-1} \mathrm{P}_{2} \mathrm{O}_{5}$ e NA (nitrato de amônio): $399 \mathrm{~kg} \mathrm{ha}^{-1} \mathrm{~N}$;

T8 - FO (farinha de ossos): $750 \mathrm{~kg} \mathrm{ha}^{-1} \mathrm{P}_{2} \mathrm{O}_{5}$ e NA (nitrato de amônio): $399 \mathrm{~kg} \mathrm{ha}^{-1} \mathrm{~N}$;

${ }^{2 *} \mathrm{e}^{* *}$ significativo a $5 \%$ e $1 \%$ de probabilidade respectivamente; ${ }^{\text {ns }}$ não significativo

${ }^{3}$ D.M.S. (5\%): diferença mínima significativa a $5 \%$ de probabilidade.
}

\section{CONCLUSÕES}

1. Há efeito positivo das fontes orgânica e mineral de $\mathrm{N}$ e $\mathrm{P}$ na produtividade e no desenvolvimento da rúcula. As fontes de nutrientes têm efeito mais pronunciado do que as doses.

2. A ação dos fertilizantes orgânicos para a rúcula é melhor quando aplicados exclusivamente em pré-semeadura, sendo, porém, inferior ao dos fertilizantes minerais.

3. A farinha de casco e chifres e a farinha de ossos de bovinos são eficazes para o desenvolvimento e produção de tomate.

\section{AGRADECIMENTO}

Os autores agradecem a colaboração do Engenheiro Agrônomo Márcio Schwingel pela tradução de literatura em inglês e alemão sobre o tema estudado e à Dr. ${ }^{\text {a }}$ Maria do Carmo de Salvo Soares Novo pelo apoio logístico ao trabalho.

\section{REFERÊNCIAS}

BRASIL, Ministério da Agricultura. Laboratório de Referência Vegetal (LANARV). Análise de corretivos, fertilizantes e inoculantes: métodos oficiais. Brasília, 1983. 104p. 
CAMARGO, A.M.M.P.; CASER, D.V.; CAMARGOFILHO, W.P.; CAMARGO, F.P.; COELHO, P.J. Área cultivada com agricultura orgânica no estado de São Paulo, 2004. Informações Econômicas, São Paulo, v.36, n.3, p.33-62, 2006.

CATANI, R.A.; NASCIMENTO, A.C.; COSTA, N.A. Fertilizantes nitrogenados, classificação e análise. In. REUNIÃO BRASILEIRA DE CIÊNCIA DO SOLO, 4., 1953, Belo Horizonte. Anais... Belo Horizonte: Sociedade Brasileira de Ciência do Solo, p.65-82, 1956.

DIAS, R.P. Pró-Orgânico. 2007. Disponível em www.agricultura.gov.br/pls/portal/docs/page/mapa/ menu_lateral/agricultura_pecuaria/produtos. Acesso em 11 dez 2007.

EMBRAPA. Centro Nacional de Pesquisa de Solos (RJ). Sistema Brasileiro de Classificação de Solos. Brasília: Embrapa Solos, XXVI, 1999. $412 \mathrm{p}$.

ESPÍNDOLA FILHO, A. Aproveitamento de resíduos sólidos de pescado como fertilizante marinho. 1998. 98f. Dissertação (Mestrado) - Universidade Presbiteriana Mackenzie, São Paulo.

KAMIYAMA, A. Introdução à Agricultura Orgânica. In. SEMINÁRIO REGIONAL DE AGRICULTURA SUSTENTÁVEL, 2005, Mogi das Cruzes. Anais... Mogi das Cruzes: Coordenadoria de Assistência Técnica Integral (CATI) EDR, 2005. p.33-41.

KIEHL, E.J. Fertilizantes Orgânicos. Piracicaba: Agronômica Ceres, 1985. $492 \mathrm{p}$.

LABER, H. N-Freisetzung aus organischen Handelsdünger Übersicht ung eigene Versuchsergebnisse im ökologischen Gemüsebau. Tagungsband zum Statusseminar "Ressortforschung für den ökologischen Landbau - Aktivitaten aus Bund und Lander", marz 2003, Forum der Bundesforschungsanstalt für Landwirtschaft (FAL), Braunschweig, Landbauforschung Völkenrode, FAL Agricutural Research, Sonderheft 259, Seite (n) 17-20. 2003. Disponível em: http://orgprints.org/00002041/. Acesso em 7 dez 2005.

MELLO, S.C.; VITTI, G.C. Influência de materiais orgânicos no desenvolvimento do tomateiro e nas características químicas do solo em ambiente protegido. Horticultura Brasileira, Brasília, v.20, n.3, p.452-458, 2002.

MELO, W.J.; MARQUES, M.O. Potencial do lodo como fonte de nutrientes para as plantas. In: BETTIOL, W.; CAMARGO, O.A. (Eds.) Impacto ambiental do uso agrícola do lodo de esgoto. Jaguariúna: EMBRAPA Meio Ambiente, 2000. p.109-142.

NOGUEIRA, M.C.S. Curso de estatística experimental aplicado à experimentação agronômica.Piracicaba: Departamento de Matemática e Estatística, Esalq, 1991. 168p.

SINIGAGLIA, C.; RODRIGUES NETO, J.; COLARICCIO, A.; VICENTE, M.; GROPPO, G.A.; GRAVENA, S.; LEITE, D. Manejo Integrado de Pragas e Doenças do Tomateiro. São Paulo: Secretaria de Agricultura e Abastecimento, 2000. v.6. 66p. (Manual Técnico, Série Especial)
TRANI, P.E.; NAGAI, H.; PASSOS, F.A. Tomate estaqueado. In: RAIJ, B. van; CANTARELLA, H.; QUAGGIO,J.A.;FURLANI, A.M.C. (Eds.) Recomendações de Adubação e Calagem para o Estado de São Paulo. 2.ed.rev.atual. Campinas: Instituto Agronômico/ Fundação IAC. 1997a. p.183-184 (Boletim técnico, 100)

TRANI, P.E.; PASSOS, F.A.; AZEVEDO FILHO, J.A. de. Alface, almeirão, chicória, escarola, rúcula e agrião d'água. In: RAIJ, B. van; CANTARELLA, H.; QUAGGIO, J.A.; FURLANI, A.M.C. (Eds.) Recomendações de Adubação e Calagem para o Estado de São Paulo. 2. ed. rev. atual. Campinas: Instituto Agronômico/ Fundação IAC. 1997b. p.168-169 (Boletim técnico, 100).

WILLER, H.; MINOU, Y. The world of organic agriculture: statistics \& emerging trends 2006, 21p. 2006. Disponível em: www.orgprints.org/5161/01/yussefi_2006_?overview.pdf. Acesso em: 11 dez 2007.

WILLER, H.; MINOU, Y The world of organic agriculture: statistics and emerging trends 2007. 2007. Disponivel em: www.organicresearcher.com/2007/02/23/world-organicstatistics-2007. Acesso em: 11 dez 2007. 